\title{
Digitalização de documentos, direitos digitais e garantia de projetos de qualidade: modelo de produtividade para arquivos, bibliotecas e museus.
}

\author{
Pablo Soledade ${ }^{1}$, Zeny Duarte de Miranda² \\ ${ }^{1}$ https://orcid.org/0000-0001-5324-3135. Universidade Federal da Bahia, Salvador, \\ Bahia, Brasil. pablosoledade@gmail.com. \\ 2 https://orcid.org/0000-0003-0365-6905. Universidade Federal da Bahia, Salvador, \\ Bahia, Brasil. zenydu@gmail.com.
}

\section{Resumo:}

Trata-se de pesquisa cujo objetivo é demonstrar apontamentos para a sistematização e aplicabilidade de um Modelo de Produtividade de Digitalização (MPD) aos documentos arquivísticos, bibliográficos e museológicos, corroborando com a ampliação do acesso à informação, ancorado sob a ótica dos direitos digitais tendo como ponto fundamental as ações de preservação de acervos documentais de unidades de informação. Essa pesquisa, com base num arcabouço teórico, prático e jurídico, vislumbra disponibilizar conteúdo para garantir melhores práticas em projetos de digitalização, no sentido de possibilitar produtividade, interseção harmoniosa entre quantidade e qualidade dos trabalhos que vem sendo executados por instituições e pessoas. Os resultados preliminares, visto ser uma pesquisa em andamento, evidenciam melhoria na produtividade, e que esse modelo pode ser utilizado em projetos de digitalização tanto para acervos de arquivos, bibliotecas, quanto de museus. A metodologia apresenta-se como pesquisa documental, analisando relatórios de produção em projetos para identificação dos pontos essenciais. A digitalização de documentos, também conhecida como transladação ou conversão digital, segundo o Dicionário de Terminologia Arquivística (DIBRATE, 2005) é o processo de conversão de um documento para o formato digital por meio de dispositivo apropriado, como um escâner. Entende-se, no entanto, que não ocorre bem uma transformação, e sim a geração de um representante digital. Se tomarmos o exemplo da fotografia, ficará fácil a compreensão deste fenômeno, ao fotografarmos uma pessoa num banco da praça, ao reproduzirmos esta imagem na tela de nosso celular, ocorre ali a captura da representação desta pessoa, e não uma transformação ou conversão desta pessoa para um outro formato. A pessoa continua existindo, da mesma forma física, ou seja, não foi transformada, não foi desmaterializada. A discussão sobre materialização ou desmaterialização é por demais complexa para determinarmos como conceitos concretos para este processo de digitalização, na qual entende-se representada sob a ótica da representação da informação. Os resultados da pesquisa em andamento apontam também que a digitalização de documentos vem sendo realizada de forma 
pragmática pelas pessoas e inclusive por empresas que se dizem especializadas, mas não possuem o domínio jurídico, teórico e práticos necessários. É hora de digitalizar com qualidade. Essa frase permeia esta discussão, nela estão embutidos princípios e práticas que atrelam elementos da Administração, especialmente da Gestão de Projetos, Tecnologia da Informação e Comunicação (TIC), aliadas à Arquivologia, Biblioteconomia e Museologia. Entende-se que a digitalização de documentos envolve as etapas de recepção, conferência, preparo, captura, indexação, controle de qualidade, remontagem e devolução do documento. Denota-se a falta na literatura brasileira de termo que venha englobar todo o processo, visto que este traz uma compreensão de "tornar digital", destacada no DIBRATE. A captura da imagem tornase aparentemente o único ponto a focar, o único momento do "digitalizar". Mas, e as outras etapas mencionadas? Utilizou-se como referencial normas do Conselho Nacional de Arquivos, a legislação brasileira, o guia Project Management Body of Knowledge (PMBOK) para gerenciamento de projetos, teses, dissertações e artigos de autores com relevantes trabalhos produzidos na temática digitalização e gerenciamento eletrônico de documentos.

Palavras-chave: Digitalização de documentos. Direitos digitais. Projetos de digitalização. Qualidade em projetos. Documentos digitalizados.

\section{Abstract:}

It is a research whose objective is to demonstrate notes for the systematization and applicability of a Scanning Productivity Model (MPD) to archival, bibliographical and museological documents, corroborating with the expansion of access to information, anchored from the point of view of digital rights. as a fundamental point the actions of preservation of documentary collections of information units. This research, based on a theoretical, practical and legal framework, envisages providing content to guarantee best practices in digitalisation projects, in the sense of enabling productivity, harmonious intersection between quantity and quality of the works that are being performed by institutions and individuals. The preliminary results, since this is an ongoing research, show improvement in productivity, and that this model can be used in digitalization projects for both archives, libraries and museums. The methodology is presented as documentary research, analyzing production reports in projects to identify the essential points. Scanning of documents, also known as translation or digital conversion, according to the Dictionary of Archival Terminology (DIBRATE, 2005) is the process of converting a document to the digital format through an appropriate device such as a scanner. It is understood, however, that a transformation does not occur well, but the generation of a digital representative. If we take the example of photography, it will be easy to understand this phenomenon, when photographing a person on a bench in the square, reproducing this image on the screen of our cellphone, there occurs the capture of the representation of this person, not a transformation or conversion of this person to 
another format. The person continues to exist, in the same physical way, that is, it has not been transformed, it has not been dematerialized. The discussion about materialization or dematerialization is too complex to determine as concrete concepts for this process of digitization, in which it is understood represented from the viewpoint of information representation. The results of the ongoing research also point out that the digitalization of documents has been carried out in a pragmatic way by people and even by companies that claim to be specialized, but do not have the necessary legal, theoretical and practical domain. It's time to scan with quality. This phrase permeates this discussion, in it are embedded principles and practices that tie elements of the Administration, especially Project Management, Information Technology and Communication (ICT), allied to Archivology, Library Science and Museology. It is understood that document scanning involves the steps of reception, conference, preparation, capture, indexing, quality control, reassembly and return of the document. It is denoted the lack in the Brazilian literature of a term that encompasses the entire process, since it brings an understanding of "digital rendering", highlighted in DIBRATE. Capturing the image apparently becomes the only point to focus on, the only time to "scan". But what about the other steps mentioned? The guidelines of the National Council of Archives, the Brazilian legislation, the Project Management Body of Knowledge (PMBOK) guide for management of projects, theses, dissertations and articles by authors with relevant works produced in the thematic scanning and electronic document management.

Keywords: Document scanning. Digital rights. Scanning projects. Quality in projects. Digitalized documents. 


\section{INTRODUÇÃO}

Este trabalho apresenta apontamentos para a sistematização e aplicabilidade de um Modelo de Projeto de Digitalização (MPD) para documentos. Tem por base experiências em projetos de digitalização realizados a partir da implementação de conceitos e práticas advindas das ações disciplinares ou multi da Arquivologia, Biblioteconomia, Administração e TIC, trazendo especialmente as práticas e conceitos da gestão de projetos do $P M B O K^{1}$. O MPD encontra-se em fase de testes em acervos arquivísticos e não-arquivísticos (suporte em papel, sem características de organicidade e relação com as funções institucionais), bibliográficos e museológicos, a princípio demonstrando-se abrangentes para as áreas.

Antes de mais nada é necessário esclarecer o que se entende por digitalização. Conhecida também como transladação, digitalizar, segundo o Dicionário de Terminologia Arquivística (DTA, 2005) é o processo de conversão de um documento para o formato digital por meio de dispositivo apropriado, como um escâner. No entanto, compreende-se que não ocorre bem uma transformação, e sim a geração de um representante digital. Se tomarmos o exemplo da fotografia, ficará fácil a compreensão deste fenômeno, ao fotografarmos uma pessoa num banco da praça, ao reproduzirmos esta imagem na tela de nosso celular, ocorreu ali a captura da representação desta pessoa, e não uma transformação ou conversão desta pessoa para um outro formato. A pessoa continua existindo, da mesma forma física, ou seja, não foi transformada, não foi desmaterializada.

A discussão sobre materialização ou desmaterialização é por demais complexa para determinarmos como conceitos concretos para este processo de digitalização, na qual entende-se representada sob a ótica da representação da informação. Sobre materialidade, Frohmann (2008) apresenta esta característica como ponto fundamental da informação, destacando a necessidade de valorização da

\footnotetext{
${ }^{1}$ Guia de gerenciamento de projetos do Project Management Institute (PMI, 2017)
}

IX Encontro Ibérico EDICIC (Barcelona, entre 9 e 11 de julho de 2019) 
documentação, visto ser elemento que dá a materialidade a informação, mas não significa que isto é físico. Frohmann faz uma correlação entre documentos e enunciados, reverberados por Foucault (1986), apesar de deixar claro que enunciado não é documento, mas expressa que os recursos teóricos de massa, energia e força, são campos vastos para a materialidade da informação, e aponta inclusive a identificação destes recursos na perspectiva da documentação.

Entende-se que a digitalização envolve as etapas de recepção, conferência, preparo, captura, indexação, controle de qualidade, remontagem e devolução do documento. Denota-se a falta na literatura brasileira de termo que venha englobar todo o processo de digitalização, visto que traz uma compreensão de "tornar digital", destacada no DTA. Neste aspecto, a captura da imagem torna-se aparentemente o único ponto a focar, o único momento do "digitalizar". Mas, e as outras etapas que envolvem o processo? Enquanto não temos semanticamente tal termo, vamos entender a digitalização como o conjunto de processos que propicia a derivação de um representante digital de um documento em estado analógico. Tal processo é iniciado pela recepção do documento e concluído com a devolução do lote para a destinação final.

É relevante destacar que neste trabalho não está sendo defendida a digitalização de tudo, pelo contrário, a decisão da instituição digitalizar um acervo, perpassa por uma análise criteriosa de benefícios e impactos, no sentido mais amplo. Estamos nos referindo aos documentos digitalizados e não aos natodigitais, que possuem outro universo, visto o status quo da originalidade, tornando-se condição sine qua non para estes a manutenção da sua autenticidade. Já os digitalizados, pressupõem seu uso a partir da perspectiva da Lei Federal 12.682/2012, onde os mesmos têm validade jurídica, seguindo os critérios determinados, mas no entanto, devendo-se manter o documento original - Art. 60, "os registros públicos originais, ainda que digitalizados, deverão ser preservados de acordo com o disposto na legislação pertinente". Pinheiro (2016), demonstra juridicamente que os documentos eletrônicos já possuem valor probante. Argumenta que o ideal é que documentos já 
nasçam digitais e não que sejam digitalizados, sob pena de perderem a integridade. Ressalta que o processo de digitalização simples gera necessidade de prova pericial e que estas questões podem ser solucionadas através de Cartórios.

Corroborando com esta visão, Luz (2018):

O documento digitalizado (o representante digital de um documento) pode ser um documento autenticado mas nunca será um documento autêntico por não possuir as características diplomáticas. Logo, a forma de garantir as características diplomáticas dos documentos nos ambientes digitais passa por manter uma cadeia de custódia de um ambiente de gestão ao ambiente de preservação, incorporando os documentos natodigitais como prioridade.

Nesta visão de Luz, assim como Flores, 2013, entre outros autores da área, os documentos digitalizados não possuem os dois elementos necessários para garantia da autenticidade, ou seja, identidade e integridade. A identidade seria possível e provável, se utilizarmos os certificados digitais e assinaturas eletrônicas amparados pela MP 2200-2, que institui a Infra-Estrutura de Chaves Públicas Brasileira - ICP-Brasil, bem como a já referida Lei 12.682/2012. Mas, a integridade seria algo possível apenas para os documentos já nascidos em ambientes digitais, ou seja, os natodigitais, pelos elementos e características diplomáticas existentes deste o processo de produção documental.

Todavia, será mesmo que os documentos digitalizados não podem conter tais elementos de integridade? Será que não podem absorver tais características quando da realização do processo de digitalização de documentos, a partir das mais diversas técnicas existentes, como por exemplo, optical character recognition (ocr), inteligente character recognition (icr), blockchain, dentre tantas outras existentes e a existir, sempre embasadas num rigoroso controle de qualidade e inspeção, e também necessariamente fidedignidade e autenticidade? Os rigorosos controles também não são característicos da produção dos documentos natodigitais?

Obviamente que a tarefa de atribuir integridade ao documento digitalizado não é fácil, e parece gozar de complexidade certas vezes maior do que a própria gestão de documentos natodigitais. Mas, o universo da pesquisa científica nos permite parar em obstáculos epistemológicos (Bachelard, 2006), que nos impeçam de enxergar, refletir e questionar? Uma pesquisa se depara ou ao menos deveria se deparar com pontos 
que geram profunda inquietação e inclusive aversão da própria comunidade científica. Essas inquietações certas vezes impõem quebras de paradigmas e aberturas para linhas de pensamentos até então rechaçadas.

A MP 881/2019 que institui a Declaração de Direitos de Liberdade Econômica, estabelece garantias de livre mercado, análise de impacto regulatório, e dá outras providências, altera a já citada Lei 12.682/2012 e apresenta em seu Art. 11 a possibilidade do descarte do documento original após a digitalização. Esta situação coloca já uma necessidade prática a solucionar das reflexões trazidas acima. Vejamos

Art.11. $\S 1^{\circ}$ Após a digitalização, constatada a integridade do documento digital nos termos estabelecidos no regulamento, o original poderá ser destruído, ressalvados os documentos de valor histórico, cuja preservação observará o disposto na legislação específica.

Tal situação propicia insegurança jurídica, visto que ainda não temos no cenário atual processos consolidados e amadurecidos que garantam autenticidade ao documento digitalizado. A alteração da lei possibilita também uma interpretação ambígua, visto que não foi suprimido o art. $6^{\circ}$ desta, e por esta razão, mantém-se a necessidade da preservação do original, mesmo que não seja de valor histórico, mas por razões legais. São questões ainda embrionárias, e que merecem atenção e profundidade de discussão jurídica, mas também conceitual.

Ferrari (2014) destaca a relação de direitos e deveres digitais, trazendo uma discussão sobre a relevância do acesso aberto, desta forma traçamos uma correlação positiva entre digitalização, acesso aberto e direitos digitais.

IX Encontro Ibérico EDICIC (Barcelona, entre 9 e 11 de julho de 2019) 


\section{METODOLOGIA}

Este trabalho tem por base a pesquisa documental, a partir da análise de relatórios mensais de produção em projetos de digitalização para identificação dos pontos pesquisados. Foram selecionadas 1 instituição de cada área (arquivo, biblioteca e museu), que por motivos de sigilo não serão revelados o nome. Para identificação destas adotar-se-á os nomes Instituição A, B e C. Preparou-se um formulário para verificar a quantidade de digitalizações realizadas e de recusas de documentos digitalizados nos projetos, pelo controle de qualidade, necessitando-se assim de redigitalizações. O objetivo foi apresentar um quadro demonstrativo dos resultados, revelando os percentuais de ampliação ou não de produtividade em etapas do processo de digitalização após a aplicação do MPD.

\section{PRODUTIVIDADE NOS PROJETOS DE DIGITALIZAÇÃO}

A produtividade é uma das melhores medidas para aferir a performance organizacional de uma instituição. Uma corporação torna-se mais eficiente, atingindo melhores resultados utilizando seus recursos com eficácia, tendo assim perspectivas mais alvissareiras. Peter Drucker (2002), numa visão gerencial, afirma que produtividade é um dos melhores indicadores para comparar a eficácia. Marx (apud Andrade, 2000, p.107), aponta para uma visão mais social correlacionando aspectos de ampliação da mais-valia pelo maior uso e produtividade da força de trabalho.

Buscando aproveitar elementos importantes destas duas visões, adota-se neste trabalho a visão de Burd (2017) no qual apresenta produtividade como

"o resultado obtido quando algo ou alguém possui a qualidade de ser produtivo. Identifica-se como produtivo aquele que fez mais e que ofereceu um resultado maior ou melhor gastando menos. Um exemplo prático seria produzir mais de um determinado produto usando menos horas, energia, água ou quaisquer outros insumos." (grifos nossos).

Os indicadores da produtividade estão relacionados a busca de melhores resultados em processos internos, e para geração de produtos ou serviços. Trazendo 
para realidade dos processos de digitalização, podemos dizer que a melhor produtividade é encontrada quando realiza-se maior quantidade de digitalizações, com a qualidade desejável, em menor tempo. A digitalização é um processo contínuo, de linha de produção, exigindo claras definições de tarefas e fluxos. Quem faz o quê? Como, quando? Onde, por quê? A seguir apresenta-se um gráfico correlacionando produtividade com o período de execução do projeto.

\section{Gráfico 1 - Curva de produtividade em projetos de digitalização}

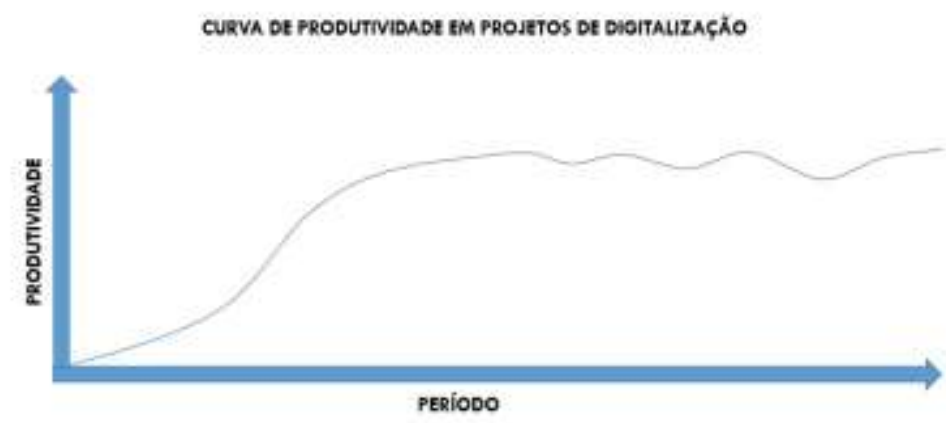

Fonte: próprio autor, 2018.

O Gráfico foi elaborado a partir da análise de resultados do processo de digitalização, avaliando a produtividade mensal do projeto, no período de 12 meses. A reta $X$ (produtividade) representa o volume de digitalização e a reta $Y$ (período) 0 tempo evolutivo deste projeto. Nota-se com o passar do tempo, uma significativa ampliação dos resultados, revelando um grau de maturidade da equipe quanto ao conhecimento do processo, e enfim, uma produção quase linear, atingindo um pico de produtividade. No entanto, percebe-se que a equipe não consegue manter o mesmo nível de produção, após atingir esse pico, há uma série de variáveis que podem corroborar com esta oscilação, como ausências de funcionários, quebra de equipamentos, documentos em estado de conservação mais críticos, exigindo tratamento documental, etc. Tais elementos devem ser controlados pelo Gerente do Projeto, e constar num Plano de Gerenciamento de Riscos. Podemos dizer que a produtividade nos projetos de digitalização está relacionada a definição de metas; planejamento; recursos disponibilizados (humanos, materiais, financeiros); grau de 
amadurecimento da equipe; execução das ações planejadas, monitoramento e controle das ações.

\section{APONTAMENTOS PARA UM MPD}

Apresenta-se desta forma os apontamentos preliminares para a constituição científica do MPD a ser proposto. Identifica-se um ciclo básico do processo de digitalização, composto pelos seguintes elementos.

\section{Figura 1}

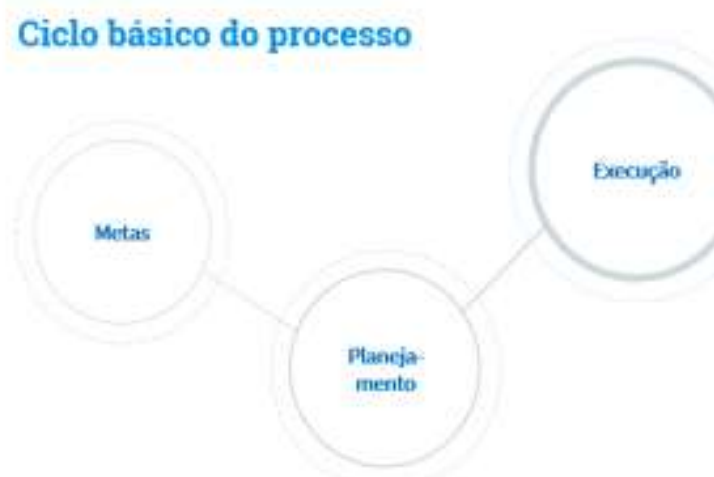

Fonte: próprio autor, 2018

\section{RESULTADOS}

O estudo revelou resultados satisfatórios quando aplicado em uma instituição, cujo por motivos de sigilo não podemos revelar o nome, tanto para digitalizações de acervos arquivísticos, não-arquivísticos e biblioteconômicos. A seguir apresenta-se um quadro demonstrativo. Em todos os itens apresentaram-se significativas melhorias. Os percentuais negativos significam também bons resultados, pois demonstra a redução de "retrabalhos" 


\begin{tabular}{lc}
\hline ETAPAS & \%AMPLIAÇÃO \\
\hline Recepção e conferência & $15 \%$ \\
\hline Preparação (tratamento) & $21 \%$ \\
\hline Nova preparação & $-30 \%$ \\
\hline Captura de documentos & $23 \%$ \\
\hline Nova captura por falhas na inicial & $-32 \%$ \\
\hline Indexação & $18 \%$ \\
\hline Reindexação & $-58 \%$ \\
\hline Remontagem & $16 \%$ \\
\hline
\end{tabular}

\section{CONSIDERAÇÕES FINAIS}

A decisão de realizar um projeto de digitalização perpassa por uma avaliação rigorosa. Justificar a necessidade de digitalização pela redução de custos é falacioso. Verifica-se que antes de qualquer processo é necessário pensar na gestão do acervo de forma mais ampla. Não adianta digitalizar sem uma organização prévia da documentação física e sem o estabelecimento de políticas internas, independente do porte da organização. Projetos de digitalização envolvem custos, de milhões a depender do volume documental que se está trabalhando. Acesso, segurança, compliance e preservação são uma tétrade necessária em projetos de digitalização de documentos. Destaca-se também a necessidade do conhecimento prévio da legislação e normativas. Por fim, verifica-se um cenário propício para atuação dos profissionais de informação, que podem e devem ser pilotos deste "avião digital".

IX Encontro Ibérico EDICIC (Barcelona, entre 9 e 11 de julho de 2019) 


\section{REFERÊNCIAS}

ARELLANO, M. A. Preservação de documentos digitais. Ci. Inf., Brasília, v. 33, n. 2, p. 15-27, maio/ago. 2004.

ARELLANO, M. A. Preservação digital e os profissionais da informação. Data Grama Zero, Revista de Ciência da Informação, v. 7, n. 5, p. 1-9, out. 2006.

BACHELARD, Gaston. A epistemologia. Tradução de Fátima Lourenço Godinho e Mário Carmino Oliveira. Lisboa, Portugal: Edições 70, 2006.

BELLOTTO, H. L. Arquivos Permanentes: tratamento documental. 2ed. Rio de Janeiro: Editora da Fundação Getúlio Vargas, 2004. v. I. 318p.

; Camargo, Ana Maria de Almeida. Dicionário de terminologia arquivística. 1a ed. São Paulo: Secretaria de Estado da Cultura do Estado de São Paulo, 1996. 142p.

BRASIL. Presidência da República. Arquivo Nacional. Dicionário brasileiro de terminologia arquivística. Rio de Janeiro: [s.n], 2005.

. Presidência da República. Lei no 12.682, de 9 de julho de 2012. Dispõe sobre a elaboração e 0 arquivamento de documentos em meios eletromagnéticos. Disponível em: http://www.planalto.gov.br/ccivil_03/_ato20112014/2012/Lei/L12682.htm. Acesso em: 30 nov. 2014

. Resolução n 31, de 28 de abril de 2010. Dispõe sobre a adoção das Recomendações para Digitalização de Documentos Arquivísticos Permanentes. Disponível em: <http://conarq.arquivonacional.gov.br/images/publicacoes_textos/Recomendacoes_d igitalizacao_completa.pdf>. Acesso em: 14 jan. 2019.

- Conselho Nacional de Arquivos. Câmara Técnica de Documentos Eletrônicos. Glossário de documentos arquivísticos digitais. Rio de Janeiro: CONARQ, 2014.2 Disponível em: <http://www.conarq.arquivonacional.gov.br/images/ctde/Glossario/2014ctdeglossari o_v6_public.pdf>. Acesso em: 20 mar. 2019.

CAPURRO, R. Epistemologia e ciência da informação. In: ENCONTRO NACIONAL DE PESQUISA EM CIÊNCIA DA INFORMAÇÃO, 5., 2003, Belo Horizonte. Anais... Belo Horizonte: Ancib, 2003. Disponível em: http://www.capurro.de/enancib_p.htm. Acesso em: 22 mar. 2019.

CASTRO, Astréa de Moraes e. Arquivos físicos e digitais. Astréa de Moraes e Castro; Andresa de Moraes e Castro e Danuza de Moraes e Castro Gasparian. - Brasília: Thesaurus, 2007. 
CONSELHO NACIONAL DE ARQUIVOS (CONARQ). Carta para preservação do patrimônio arquivístico digital. Rio de Janeiro: Arquivo Nacional, 2005. Disponível em:

<http://Conarq.Conarq.arquivonacional.gov.br/images/publicacoes_textos/Carta_pre servacao.pdf>. Acesso em: 14 jan. 2019.

CONVERSÃO. In: DICIO, Dicionário Online de Português. Porto: 7Graus, 2018. Disponível em: https://www.dicio.com.br/conversao/. Acesso em: 12 abr 2019.

COOK, Terry. A ciência arquivística e o pós-modernismo: novas formulações para conceitos antigos. Revista Ciência da Informação. Ribeirão Preto, v. 3, n. , p. 327, jul/dez $2012 . \quad$ Disponível em: http://revistas.usp.br/incid/article/download/48651/52722. Acesso: 05 de março de 2019.

CORRÊA, A. M. G. Preservação digital: autenticidade e integridade de documentos em bibliotecas digitais de teses e dissertações. Dissertação (Mestrado em Ciência da Informação) 96 p, Universidade de São Paulo: São Paulo, 2010. Disponível em: $<$ http://www.teses.usp.br/teses/disponiveis/27/27151/tde-05112010-105831/ptbr.php>. Acesso em: 03 jan. 2019.

DURANTI, Luciana. "Rumo a uma teoria arquivística de preservação digital: as descobertas conceituais do Projeto InterPARES," Arquivo \& Administração. 4(1) (2005): 5-18.

FERREIRA, M. Introdução à preservação digital: conceitos, estratégias e atuais consensos. Guimarães, Portugal: Escola de Engenharia da Universidade do Minho, 2006.

FLORES, Daniel. Santos, Henrique Machado dos; Perspectivas em Ciência da Informação, v.20, n.4, p.197-217, out./dez. 2015197 Políticas de preservação digital para documentos arquivísticos Perspectivas em Ciência da Informação, v.20, n.4, p.197-217, out./dez. 2015

FLORES, D. Manutenção da autenticidade, confiabilidade e fonte de prova dos documentos arquivísticos digitais (do SIGAD ao RDC-Arq). Câmara Municipal de São Paulo. São Paulo - SP. 124 slides, color, Padrão Slides Google Drive/Docs 4x3. Material elaborado para a Palestra na Unicamp, 19 de abril de 2016. Disponível em: <http://documentosdigitais.blogspot.com>. Acesso em: 09 abr. 2019.

FLORES, D.; BAGGIO, C. C. Documentos digitais: preservação e estratégias. Biblos: Revista do Instituto de Ciências Humanas e da Informação, v. 27, n. 1, p. 1124, jan./jun. 2013.2 Disponível em: <https://periodicos.furg.br/biblos/article/view/2654/2395> Acesso em: 09 mar 2019. 
FROHMANN, Bernd. O caráter social, material e público da informação. In: FURTA, Mariangela S.L.; MARTELETO, Regina Maria; LARA, Marilda L.G. de. A dimensão epistemológica da Ciência da Informação e suas interfaces técnicas, políticas e institucionais nos processos de produção, acesso e disseminação da informação. Marília: Fundepe, 2008. P. 19-34.

GONZÁLEZ DE GÓMEZ, Maria Nélida. Novos cenários políticos para a informação. Ci. Inf., Brasília, v. 31, n. 1, p. 27-40, jan./abr. 2002

INNARELLI, H. C. Gestão de preservação de documentos arquivísticos digitais: proposta de um modelo conceitual. 2015. 348f. Tese (Doutorado em Ciências da Informação) - Escola de Comunicações e Artes, Universidade de São Paulo, São Paulo.

. Preservação digital e seus dez mandamentos. In: SANTOS, Vanderlei Batista (Org.). Arquivística: temas contemporâneos, classificação, preservação digital, gestão do conhecimento. Distrito Federal: SENAC, 2007. p. 21-75.

INTERPARES 2 PROJECT. Diretrizes do Preservador. A preservação de documentos arquivísticos digitais: diretrizes para organizações. TEAM Brasil. Tradução: Arquivo Nacional e Câmara dos Deputados. 2002 - 2007. Disponível em: $<$ http://www.interpares.org/display_file.cfm?doc=ip2_preserver_guidelines_booklet-portuguese.pdf $>$. Acesso em: 09 fev. 2019.

LUZ, Charlley. Digitalizar documentos é dar a cada usuário a informação que precisa. Disponível em https://www.linkedin.com/pulse/digitalizar-documentos$\%$ C3\%A9-dar-cada-usu\%C3\%A1rio-informa\%C3\%A7\%C3\%A3o-que-charlley-luz/. Acessado em 15jun2018.

PMI. Um guia do conhecimento em gerenciamento de projetos. Guia PMBOK. 6a ed. - EUA: Project Management Institute, 2017.

RONDINELLI, R. C. Gerenciamento arquivístico de documentos eletrônicos: uma abordagem teórica da diplomática arquivística contemporânea. 4. Ed. Rio de Janeiro: FGV, 2005.

O documento arquivístico ante a realidade digital: uma revisão conceitual necessária. Rio de Janeiro: FGV, 2013.

SANTOS, H. M. dos; FLORES, D. Políticas de preservação digital para documentos arquivísticos. Perspectivas em Ciência da Informação, Belo Horizonte, v.20, n.4, p.197-217, out./dez. 2015. Disponível em: <http://portaldeperiodicos. eci.ufmg.br/index.php/pci/article/view/2542>. Acesso em: 21 dez. 2018.

SANTOS, Vandeleri B. Preservação de documentos arquivísticos digitais. Ci. Inf., Brasília, DF, v. 41 n. 1, p.114-126, jan./abr., 2012. 
SAYÃO, L. F. Repositórios Digitais Confiáveis para a Preservação de Periódicos Eletrônicos Científicos. Ponto de Acesso, Salvador, v.4, n.3, p. 68-94, dez. 2010. Disponível http://www.portalseer.ufba.br/index.php/revistaici/article/view/4709/3565>. Acesso em: 08 fev. 2019.

SCHMIDT, Clarissa M.S. 2012 Arquivologia e a construção do seu objeto científico: concepções, trajetórias, contextualizações. Tese defendida no Programa de Pós-graduação em Ciência da Informação da Escola de Comunicações e Artes (ECA) da Universidade de São Paulo (USP). São Paulo, 2012.

SILVA, Armando Malheiro da. Arquivística: teoria e prática de uma Ciência da Informação. Porto: Edições Afrontamento, 1999.

TRANSFORMAÇÃO. In: DICIO, Dicionário Online de Português. Porto: 7Graus, 2018. Disponível em: https://www.dicio.com.br/conversao/. Acesso em: 12 abr 2019.

TRANSLADAÇÃO. In: DICIO, Dicionário Online de Português. Porto: 7Graus, 2018. Disponível em: https://www.dicio.com.br/conversao/. Acesso em: 12 abr 2019. 